\title{
Iniciativas para la formulación de normas uniformes en el ámbito del Derecho procesal civil internacional ${ }^{1}$
}

Antonio Gidi

Los litigios judiciales no son raros. Los litigios judiciales son rarísimos. Todos los días comemos en restaurantes, cogemos autobuses, compramos mercancías y establecemos relaciones contractuales de consumo, bancarias y comerciales. La gran mayoría de las veces, las transacciones se realizan sin conflictos. Tal vez, de un billón de relaciones jurídicas, solamente una termina en los tribunales.

Esto no quiere decir que los ilícitos civiles y los conflictos sean tan raros. Casi todos los días somos, o pensamos que somos, objeto de engaño o lesionados por la conducta de otras personas. Y muchas veces lo somos sin saberlo. Pero casi nunca iniciamos por ello un proceso judicial. Los motivos son tan variados como variadas son las relaciones humanas, pero las causas más comunes de esta conducta son: que los hechos resultan difíciles de probar; que el proceso es muy largo; que el proceso es caro, o que mi reclamación es de tan escasa cuantía que no merece el esfuerzo de iniciar el proceso; o, por último, la razón puede encontrarse en que si pierdo el litigio deberé asumir el pago de los honorarios del abogado del vencedor.

1 Presentación hecha en el Salón de Grados de la Facultad de Derecho de la Universidad de Barcelona, en la Jornada Internacional sobre Nuevos retos para el Derecho procesal civil internacional realizada el 5 de noviembre de 2001 y en la Facultad de Derecho de la Universidad Autónoma de México el $1^{\circ}$ de marzo de 2002. El autor desearía agradecer la amable invitación de los profesores Alegría Borrás, Joaquim Forner, Cristina Pellise y Jorge Sánchez Cordero.

Este artículo fue originalmente escrito en español, y ha contado con la revisión de María Camila Morilla, estudiante en la Maestría en Derecho en la Universidad de Pennsylvania. 
La decisión entre iniciar o no iniciar un proceso judicial es compleja y son muchas las variables que inciden en esta decisión. Un gran número de esas variables decisivas se encuentran reguladas por las leyes procesales. Por ello, es importante conocer el proceso y saber con anterioridad lo que nos espera. Esto puede resultar relativamente fácil si el litigio se suscita en nuestro país. Pero se convierte en algo sumamente complejo cuando el proceso ha de desarrollarse en el extranjero. A diferencia del derecho sustantivo, las normas procesales presentan numerosas diferencias en cada uno de los países. Las diferencias procesales no son solamente teóricas, sino que tienen también importantes consecuencias practicas de acceso a la justicia. Por ejemplo, sabemos que en China, Japón y Estados Unidos, la parte que es vencida en el litigio no paga los honorarios de la parte vencedora; en los Estados Unidos y en Inglaterra, los honorarios de los abogados se computan por hora y resultan enormemente elevados en la práctica; en los Estados Unidos, no solamente los honorarios de los abogados son muy elevados, sino también los costes del proceso. Otra diferencia esencial relativa al proceso civil en los Estados Unidos, se encuentra en que el demandante puede iniciar un proceso sin información ni pruebas de su pretensión, pues éstas las podrá obtener en el desarrollo del proceso a través del discovery.

Disponer de esa información es importante a la hora de decidir si iniciar o no un proceso judicial, al igual que resulta relevante para tomar la decisión de contestar la demanda o aceptar una propuesta de acuerdo. Finalmente, esa incidirá también en la decisión acerca de dónde interponer la demanda. Si el proceso americano es costoso, quizás sea preferible iniciarlo en España. Pero, si lo que busco es un amplio acceso a medios de prueba e información que se encuentran en manos del demandado, quizás sea preferible iniciar el proceso en los Estados Unidos.

Uno de los objetivos del proyecto ALI/UNIDROIT sobre Principios y Normas de Derecho Procesal Transnacional es uniformar o armonizar algunas de las normas procesales existentes en los diversos países, en lo que se refiere a las controversias internacionales. ${ }^{2}$ Es decir, su principal

2 Véase la tradución al español del Prof. Dr. Lorena Bachmaier Winter en este volumen 54 y la tradución del Prof. Aníbal Quiroga León en el volumen 52 de Derecho PUC. Aquellos interesados podrán consultar el texto original en inglés, acompañado de una introducción y comentario artículo por artículo, en la Página Web del American Law Institute. Ver http:/www.ali.org/ali/transrules.htm. 
objetivo consiste en reducir la falta de certeza y la inseguridad del extranjero que se ve obligado a litigar en un foro judicial que no le es familiar, sometido a unas leyes procesales que desconoce.

Con la reducción de la inseguridad no se persigue simplemente la protección del extranjero contra los nacionales en un proceso internacional. Las personas beneficiadas por este proyecto son fundamentalmente empresas sofisticadas, acostumbradas a realizar negocios en muchos paises. Con su experiencia y sus medios parece obvio que esas compañías no requieren una protección reforzada frente a los sujetos nacionales. Por ello puede afirmarse que el objetivo principal de este proyecto, al hacer el proceso más transparente, no es tanto proteger, sino incentivar las relaciones comerciales internacionales. ${ }^{3}$

El Proyecto está patrocinado conjuntamente por el American Law Institute (ALI) y por UNIDROIT (The International Institute for the Unification of Private Law). El ALI es una Asociación fundada en 1923 y compuesta aproximadamente por 3,400 miembros, de los cuales la mitad son abogados en ejercicio, y los demás Jueces y Profesores en disciplinas jurídicas. Se trata de una entidad única en el mundo, por su marcada participación en la reforma, desarrollo y perfeccionamiento del Derecho de los Estados Unidos de Norteamérica. Entre las obras más importantes que han sido producidas por este Instituto están innumerables "Restatements" ${ }^{4}$, o el "Uniform Commercial Code» y el "Model

3 Comparar Gerhard Walter and Samuel P. Baumgartner, Improving the prospects of the Transnational Rules of Civil Procedure Project: Some Thought on Purpose and Means of Implementation, 18 Ritsumeikan L. Rev. 169 (2001) (argumentando que en la Introdución de los Principios y Normas «se habla mucho de globalización y de la correspondiente necesidad de armonizar el derecho procesal, pero hay poca discusión sobre porqué la armonización de las leyes procesales en el mundo sería importante para esto) con Constantinos D. Kerameus, "Procedural Unification: The Need and the Limitations". En: International Perspectives on Civil Justice 50 (I.R. Scott ed., 1990) (argumentando que la necessidad de la armonización del derecho procesal en la Comunidad Europea es la falta de uniformidad en las leyes procesales que causa «distortion of free competition and alteration of the trade flown) Véase también Approximation of Judiciary Law in the European Union 46, 59 y 69-70 (Marcel Storme ed., 1994).

4 "Trabajos de doctrina, elaborados por el American Law Institute, que exponen y analizan en forma similar a un código comentado, las principales reglas jurídicas de origen jurisprudencial aplicables en los Estados Unidos en distintas materias" Guillermo Cabanellas, Lexis English-Spanish Legal Dictionary, 1991. 
Penal Codem. 5 UNIDROIT es una organización intergubernamental independiente, fundada hace más de setenta años, y cuyo objetivo es armonizar y unificar el Derecho Privado a través de Tratados y Convenciones Internacionales y leyes-modelo. UNIDROIT está compuesto por casi sesenta países-miembros y tiene su sede en Roma.

Esta jornada está dedicada al estudio de técnicas jurídicas que «pretenden responder a las necesidades del comercio internacional en un entorno económico globalizadon. La globalización es la premisa de este encuentro. No es preciso comprobar aquí el hecho notorio de que las transacciones comerciales internacionales se han multiplicado, y que también el derecho procesal necesita acompañar a la evolución de la sociedad. Se dice que el mundo se está «encogiendo». Se habla de la globalización y de la libre circulación de las mercancías. Con menos frecuencia, se habla de la libre circulación de las personas y los trabajadores. Los litigios de dimensión internacional son cada vez más frecuentes y la consecuencia natural es que debemos comenzar a pensar también en la libre circulación de las decisiones judiciales.

La necesidad de una armonización de las normas procesales se hace sentir ya desde hace algún tiempo, necesidad que perciben con mayor intensidad los abogados habituados a trabajar en causas de naturaleza transnacional. Esa necesidad está acentuada por el hecho de que, por el momento, las tentativas de armonización del derecho se han limitado casi exclusivamente a materias de contenido sustantivo. Las pocas convenciones internacionales en el área del derecho procesal se han limitado a estimular la asistencia jurídica entre los países, principalmente en lo que se refiere a las notificaciones y a la actuación probatoria en otro país, así como al reconocimiento y ejecución de sentencias extranjeras. ${ }^{6}$

5 Sobre la importancia del American Law Institute en los Estados Unidos, con especial énfasis en los Restatements, cf. Ugo Mattei, II modello di common law, p. 1613. Ver también: Geoffrey Hazard Jr., The American Law Institute: what it is and what it does, Centri di Studi e Ricerche di Diritto Companato e Straniero (CNR), 1994.

6 Cf. Antonio Gidi, Presentación del Proyecto de Normas transnacionales del Proceso Civil, Derecho PUC, vol. 52, p. 609. Cf., por ejemplo, "The Hague Convention of Taking of Evidence Abroad" (Convención de la Haya sobre la obtención de pruebas en el extranjero) y también la aún no acabada "International Jurisdiction and Foreign Judgments in Civil and Commercial Matters" (Jurisdicción Internacional y Sentencias Extranjeras en Asuntos Civiles y Comerciales). Sobre el motivo de esta indiferencia de la ley procesal, ver las opiniones de Catherine Kessedjian, First Impression of the 
El procedimiento propiamente dicho continúa estando regulado por el derecho procesal interno de cada país.

Aquí radica la importancia de este proyecto. Tal y como se expresa en los objetivos de esta jornada: «El objetivo de la jornada es presentar las principales novedades a nivel mundial y regional en el ámbito del derecho procesal civil internacional, para facilitar la interposición de acciones judiciales ante tribunales extranjeros y la libre circulación de decisiones judiciales.» A la vista de esos objetivos, llego a la conclusión de que el objetivo de este proyecto es el mismo.

Este proyecto tiene además otro objetivo importante. $\mathrm{Al}$ mismo tiempo que persigue reducir las incertidumbres y temores de los litigantes extranjeros ofreciéndoles una alternativa al arbitraje internacional, este proyecto puede ser también utilizado como base común para los procedimientos arbitrales internacionales.

Como se sabe, las actuales normas sobre arbitraje guardan silencio en lo que se refiere al procedimiento. Así, en la práctica, las reglas procesales de un arbitraje dependen, en gran medida, de la nacionalidad del árbitro que presidirá el tribunal arbitral, quien habitualmente tenderá a elegir el sistema con el cual esté más familiarizado. No es difícil imaginar que un arbitro inglés adoptará las Rules of Court inglesas, y uno alemán utilizará las normas de la ZPO como estructura procedimental de base para el proceso arbitral así como para las decisiones de contenido procesal. La adopción de las Normas Transnacionales podrá traer una cierta uniformidad en los procedimientos de arbitraje transnacionales. Las partes contratantes podrán libremente elegir que el procedimiento arbitral se rija por las Normas Transnacionales, independientemente de quién llegue a ser la persona o cuál sea la organización encargada de arbitrar la controversia.

Para comprender el alcance de este proyecto es importante aclarar que la denominación «Principios Fundamentales del Proceso Civil Transnacional" puede resultar equívoca, y quizás sería más correcto utilizar la denominación «Principios del Proceso Comercial Internacional». Aquí la palabra "principios", sin embargo, no alude únicamente a conceptos filosóficos abstractos del derecho procesal. Se incluyen princi-

Transnational Rules of Civil Procedure from Paris an The Hague, 33 Text. Int'l L.J. $477-$ 80 (1998) y de Geoffrey C. Hazard Jr., From whom no secrets are hid, 76 Texas L. Rv. 1665,1667 (1998). 
pios, pero obviamente también normas procesales concretas. En este contexto debe entenderse la palabra «fundamental»: Los principios son fundamentales solamente en el contexto de la armonización de los litigios internacionales.

En definitiva, la aplicación de este proyecto se limita a litigios comerciales internacionales. No se aplica a otros litigios civiles ni a litigios exclusivamente nacionales. ${ }^{7}$ El ámbito material de aplicación se regula específicamente en el Art. $2^{\circ}$.

Es preciso dejar claro que no estamos ante un código en el sentido que el derecho continental europeo da a esta expresión. No es un cuerpo normativo con pretensión de ser un sistema completo, se trata solamente de un conjunto de normas procesales cuya finalidad es más específica: conferir un tratamiento jurídico uniforme a los problemas más relevantes que surgen en la resolución de las controversias transnacionales, y otorgarles una disciplina jurídica uniforme en todos los países. En relación con las cuestiones no reguladas por estas normas será de aplicación lo dispuesto en las leyes locales. Como se dijo en el Art. $10^{\circ}$, "las normas procesales del foro serán de aplicación supletoria en aquellas materias no reguladas en estos Principios y Normas".

En este proyecto, cada artículo es importante, con un contenido y significado complejo, pues son el fruto del intenso debate sostenido entre abogados y profesores de numerosos países. El estudio en detalle de algunos de estos artículos podría constituir una tesis de doctorado en derecho comparado.

$\mathrm{Al}$ aproximarnos a las normas, ha de tenerse presente un dato importante: en un principio, todos tenemos una visión esencialmente selectiva de este proyecto: nos fijamos principal o exclusivamente en aquello que nos resulta diferente, mientras que aquellas normas que se asemejan a las de nuestro derecho, tendemos a considerarlas como reglas de aplicación universal, sin llegar a entender en muchas ocasiones que la adopción de esa norma representa una, a veces gran concesión de los ordenamientos jurídicos de otros países.

Para comprender el resultado y los objetivos de este proyecto, es necesario tener presente que casi todos los principios y normas son el re-

7 Véase el artículo 2.6 de las Normas que autoriza al Estado que haya adoptado este proyecto a excluir materias así como extender la aplicación de las presentes Normas a otras materias civiles transnacionales. 
sultado de un compromiso entre muchos sistemas jurídicos. El término "compromiso", sin embargo, no quiere decir la adopción del «mínimo común denominador" entre todos los sistemas. Encontrar un mínimo denominador común no es el objetivo de este proyecto. Siempre que ha sido posible, los compromisos que se han adoptado en la elaboración de este proyecto han buscado la finalidad de encontrar la mejor norma jurídica. La mayoría de las veces, las normas que creamos pueden considerarse "especies genéticamente modificadas" y como tales no existen en ningún ordenamiento jurídico. ${ }^{8}$

El proyecto se encuentra en plena evolución y la participación de los procesalistas de España es aún incipiente. Se espera que la iniciativa de la Revista Derecho PUC, de publicar el texto del proyecto en el Perú, con la traducción al español realizada por Prof. Dr. Lorena Bachmaier Winter, sirva de estímulo para una mayor participación de los procesalistas españoles en este importante proyecto.?

En este proyecto se ha intentado alcanzar una, tal vez, aún utópica o ingenua armonía entre el proceso civil de los países del civil law y los países del common law. Por ello, tal vez, este proyecto sea adelantado para nuestro tiempo. Si esto es así, sólo el tiempo lo podrá decir.

Si bien es cierto que este proyecto todavía se encuentra lejos de ofrecer un adecuado equilibrio entre los diversos sistemas, ha de reconocerse que tiene el innegable mérito de introducir técnicas, ideas e instituciones desconocidas y, en algún caso, hasta exóticas para las coordinadas nacionales. Por ello, este proyecto puede verse de momento como un trabajo de laboratorio, trabajo cuyo resultado sería muy útil que en un futuro fuera considerado como una ley procesal modelo. En este con-

8 Véase Antonio Gidi, “Vers un Procés Civil Transnational: Une Première Réponse aux Critiques», en Vers un Procès Civil Universel? Les Règles Transnationales de Procédure Civile de l'American Law Institute 139 (Philippe Fouchard ed., 2001).

9 Se invita a los interesados a efectuar una atenta lectura del Proyecto $y$ a enviar sus críticas, sugerencias o comentarios en inglés o en español a

American Law Institute

4025 Chestnut Street

Philadelphia PA, 19103

Estados Unidos

Fax: 215/243-1636

E-mail: transrules@ali.org. 
texto prestaría el proyecto su mejor contribución en una eventual armonización de las normas procesales en el nuevo siglo.

En la medida en que estemos, todos nosotros, dispuestos a aprender nuevas técnicas y a introducir y aplicarlas en nuestros sistemas, nuestro derecho progresará en una misma dirección y nos estaremos aproximando a ser, todos nosotros, vecinos cada vez menos distantes. ${ }^{10}$

10 Cf. Antonio Gidi, Presentación del Proyecto de Normas transnacionales del Proceso Civil, Derecho PUC, vol. 52, p. 620, 1999. 